\title{
Rutin administration attenuates myocardial dysfunction in diabetic rats
}

\author{
Julliano F C Guimaraes ${ }^{1}$, Bruno P Muzio ${ }^{1}$, Camila M Rosa' ${ }^{1}$, Andre F Nascimento ${ }^{1}$, Mario M Sugizaki ${ }^{1}$, \\ Ana A H Fernandes ${ }^{2}$, Antonio C Cicogna ${ }^{1}$, Carlos R Padovani ${ }^{1}$, Marina P Okoshi ${ }^{1}$ and Katashi Okoshi ${ }^{1,33^{*}}$
}

\begin{abstract}
Background: Oxidative stress plays a major role in diabetic cardiomyopathy pathogenesis. Anti-oxidant therapy has been investigated in preventing or treating several diabetic complications. However, anti-oxidant action on diabeticinduced cardiac remodeling is not completely clear. This study evaluated the effects of rutin, a flavonoid, on cardiac and myocardial function in diabetic rats.

Methods: Wistar rats were assigned into control $(C, n=14)$; control-rutin $(C-R, n=14)$; diabetes mellitus (DM, $n=16$ ); and DM-rutin (DM-R, $n=16$ ) groups. Seven days after inducing diabetes (streptozotocin, 60 mg/kg, i.p.), rutin was injected intraperitoneally once a week $(50 \mathrm{mg} / \mathrm{kg}$ ) for 7 weeks. Echocardiogram was performed and myocardial function assessed in left ventricular (LV) papillary muscles. Serum insulin concentration was measured by ELISA. Statistics: One-way ANOVA and Tukey's post hoc test.

Results: Glycemia was higher in DM than DM-R and C and in DM-R than C-R. Insulin concentration was lower in diabetic groups than controls (C $2.45 \pm 0.67 ; \mathrm{C}-\mathrm{R} 2.09 \pm 0.52 ; \mathrm{DM} 0.59 \pm 0.18 ; \mathrm{DM}-\mathrm{R} 0.82 \pm 0.21 \mathrm{ng} / \mathrm{mL}$ ). Echocardiogram showed no differences between C-R and C. DM had increased LV systolic diameter compared to C, and increased left atrium diameter/body weight (BW) ratio and LV mass/BW ratio compared to C and DM-R. Septal wall thickness, LV diastolic diameter/BW ratio, and relative wall thickness were lower in DM-R than DM. Fractional shortening and posterior wall shortening velocity were lower in DM than C and DM-R. In papillary muscle preparation, DM and DM-R presented higher time to peak tension and time from peak tension to $50 \%$ relaxation than controls; time to peak tension was lower in DM-R than DM. Under 0.625 and 1.25 mM extracellular calcium concentrations, DM had higher developed tension than $\mathrm{C}$.
\end{abstract}

Conclusion: Rutin attenuates cardiac remodeling and left ventricular and myocardial dysfunction caused by streptozotocin-induced diabetes mellitus.

Keywords: Diabetes mellitus, Anti-oxidant, Cardiac remodeling, Papillary muscle, Rat, Flavonoid

\section{Background}

Diabetes mellitus is an important public health problem because of a high prevalence and increased morbidity and mortality. Cardiovascular involvement is frequent in diabetes and a major cause of death in diabetic patients $[1,2]$. Cardiac alterations are caused by both coronary atherosclerosis and diabetes-related cardiomyopathy. As

\footnotetext{
*Correspondence: katashi@fmb.unesp.br

${ }^{3}$ Departamento de Clinica Medica, Faculdade de Medicina de Botucatu,

UNESP Rubiao Junior, S/N 18618-970, Botucatu, SP, Brazil

Full list of author information is available at the end of the article
}

first reported by Rubler et al. [3], diabetic cardiomyopathy is characterized by left ventricular systolic and diastolic dysfunction in the absence of underlying coronary artery disease and/or systemic arterial hypertension [4]. Diabetic cardiomyopathy may affect both type 1 and 2 diabetic patients [5]. The pathophysiology of diabetic cardiomyopathy is multifactorial and includes several mechanisms such as myocardial fibrosis, myocyte hypertrophy, contractile dysfunction, changes in calcium handling and mitochondrial function, impaired nitric oxide signaling, and abnormal cardiomyocyte loss by apoptosis [5-7]. Despite all these mechanisms, oxidative stress is 
widely considered a major cause in the pathogenesis of diabetic cardiomyopathy [8-10].

In diabetes, oxidative stress can be induced by hyperglycemia, hyperlipidemia, and inflammation. Oxidative stress occurs when the production of reactive oxygen species exceeds their degradation by anti-oxidant defenses $[9,11]$. Anti-oxidant therapy has been extensively studied to prevent or treat several diabetic complications [12-14]; however, direct investigations on the role of anti-oxidants on diabetic-induced cardiac remodeling remain relatively scarce [9].

Flavonoids are natural substances with variable phenolic structures that have been used for their anti-oxidant properties [15]. In diabetic rats, flavonoids reversed cardiac dysfunction and structural changes and attenuated oxidative stress and cardiac dysfunction induced by ischemia-reperfusion injury [16, 17]. More than 4,000 varieties of flavonoids have been identified $[15,18]$. One of the main flavonoids is rutin, which can be extracted from many nature sources, including buckwheat, oranges, grapes, lemons, limes, peaches, and berries [19]. Recently, rutin was shown to attenuate oxidative stress, apoptosis, and inflammation in diabetic rat hearts [19]. In this study, we evaluated the effects of rutin on cardiac and myocardial function in rats with streptozotocininduced diabetes.

\section{Methods}

Male Wistar rats weighing 300-350 g were purchased from the Central Animal House at Botucatu Medical School, UNESP. All animals were housed in a temperature controlled room $25 \pm 2^{\circ} \mathrm{C}$ and kept on a $12 \mathrm{~h}$ light/dark cycle. All experiments and procedures were approved by Botucatu Medical School Ethics Committee, Sao Paulo State University, UNESP, and performed in compliance with the ARRIVE guidelines on animal research [20].

Diabetes was induced by intraperitoneal injection of streptozotocin (STZ, Sigma, St. Louis, MO, USA) at a dose of $60 \mathrm{mg} / \mathrm{kg}$ body weight, dissolved in $0.1 \mathrm{M}$ citrate buffer, pH $4.5[21,22]$. Forty-eight hours after STZ administration, blood glucose was measured by glucometer (Boehringer Mannheim, Eli Lilly Ltd., São Paulo, Brazil). Only STZ-treated rats with glycemia $>250 \mathrm{mg} / \mathrm{dL}$ were considered diabetic and included in the study [23]. Rats were randomly assigned into four groups:

1. control group $(C, n=14)$-rats treated with vehicle;

2. control-rutin $(C-R, n=14)$ group-rats treated with rutin;

3. diabetes mellitus ( $D M, n=16$ ) group-diabetic rats treated with vehicle;
4. DM-rutin (DM-R, $\mathrm{n}=16)$ group-diabetic rats treated with rutin.

Seven days after STZ injection, rutin (Sigma, St. Louis, MO, USA) was administered once a week at a dose of $50 \mathrm{mg} / \mathrm{kg}$ body weight, for 7 weeks. Rutin was solubilized in $500 \mu \mathrm{L}$ of propylene glycol; the volume was then completed to $500 \mu \mathrm{L}$ with water and injected intraperitoneally. Food and water were supplied ad libitum. To adjust rutin dose, individual rat food $(\mathrm{g})$ and water $(\mathrm{mL})$ intake was measured daily. Body weight was measured weekly. At the end of experimental period (56 days), rats were fasted for $12 \mathrm{~h}$, anesthetized, and decapitated.

\section{Echocardiographic study}

Echocardiographic evaluation was performed at the end of the study using a commercially available echocardiograph (General Electric Medical Systems, Vivid S6, Tirat Carmel, Israel) equipped with a $5-11.5 \mathrm{MHz}$ multifrequency probe, as previously described [24-26]. Rats were anesthetized by intramuscular injection of a ketamine $(50 \mathrm{mg} / \mathrm{kg})$ and xylazine $(0.5 \mathrm{mg} / \mathrm{kg})$ mixture. A two-dimensional parasternal short-axis view of the left ventricle (LV) was obtained at the level of the papillary muscles. M-mode tracings were obtained from short-axis views of the LV at or just below the tip of the mitral-valve leaflets, and at the level of the aortic valve and left atrium. M-mode images of the LV were printed on a black-and-white thermal printer (Sony UP-890MD) at a sweep speed of $100 \mathrm{~mm} / \mathrm{s}$. All LV structures were manually measured by the same observer (KO) according to the leading-edge method of the American Society of Echocardiography. Means were obtained from measurements of at least five cardiac cycles on the M-mode tracings. The following structural variables were measured: LV diastolic and systolic diameters (LVDD and LVSD, respectively), LV diastolic posterior wall thickness (PWT), LV diastolic septal wall thickness (SWT), and left atrium diameter (LA). Left ventricular mass (LVM) was calculated using the formula $\left[(\mathrm{LVDD}+\mathrm{PWT}+\mathrm{SWT})^{3}\right.$ $\left.-(\mathrm{LVDD})^{3}\right] \times 1.04 . \mathrm{LV}$ relative wall thickness $(\mathrm{RWT})$ was calculated by the formula $2 \times$ PWT/LVDD. LV function was assessed by the following parameters: endocardial fractional shortening (FS), posterior wall shortening velocity (PWSV), early and late diastolic mitral inflow velocities (E and A waves), and E/A ratio [27].

\section{Myocardial functional study}

One day after the echocardiographic study, myocardial intrinsic contractile function was evaluated in isolated LV papillary muscles as previously described [28-30]. Rats were anesthetized (pentobarbital sodium, $50 \mathrm{mg} / \mathrm{kg}$, 
intraperitoneally) and decapitated. Hearts were quickly removed and placed in oxygenated Krebs-Henseleit solution at $28^{\circ} \mathrm{C}$. $\mathrm{LV}$ anterior or posterior papillary muscle was dissected free, mounted between two spring clips, and placed vertically in a chamber containing Krebs-Henseleit solution at $28^{\circ} \mathrm{C}$ and oxygenated with a mixture of $95 \% \mathrm{O}_{2}$ and $5 \% \mathrm{CO}_{2}$ (pH 7.38). Krebs-Henseleit solution composition in $\mathrm{mM}$ was as follows: $118.5 \mathrm{NaCl}, 4.69 \mathrm{KCl}, 2.50$ $\mathrm{CaCl}_{2}, 1.16 \mathrm{MgSO}_{4}, 1.18 \mathrm{KH}_{2} \mathrm{PO}_{4}, 5.50$ glucose, and 25.88 $\mathrm{NaHCO}_{3}$. The spring clips were attached to a Kyowa model 120T-20B force transducer and a lever system, which allowed for muscle length adjustment. Preparations were stimulated 12 times/min at a voltage $10 \%$ above threshold.

After a 60 min period, during which preparations were permitted to shorten while carrying light loads, muscles were loaded to isometrically contract and stretched to the apices of their length-tension curves. After a $5 \mathrm{~min}$ period, during which preparations performed isotonic contractions, muscles were again placed under isometric conditions, and the apex of the length-tension curve $\left(\mathrm{L}_{\max }\right)$ was determined. A 15 min period of stable isometric contraction was imposed prior to the experimental period. One isometric contraction was then recorded for later analysis.

The following parameters were measured from isometric contraction: peak of developed tension $\left(\mathrm{DT}, \mathrm{g} / \mathrm{mm}^{2}\right)$, time to peak of tension (TPT, ms), time from peak tension to $50 \%$ relaxation $\left(\mathrm{RT}_{1 / 2}\right)$, maximum rate of tension development $\left(+\mathrm{dT} / \mathrm{dt}, \mathrm{g} / \mathrm{mm}^{2} / \mathrm{s}\right)$, and maximum rate of tension decline $\left(-\mathrm{dT} / \mathrm{dt}, \mathrm{g} / \mathrm{mm}^{2} / \mathrm{s}\right)$. Myocardial function was also evaluated under different extracellular $\mathrm{Ca}^{2+}$ concentrations [31, 32].

Papillary muscle cross-sectional area was calculated from muscle weight and length by assuming cylindrical uniformity and a specific gravity of 1.0. All force data were normalized for muscle cross-sectional area [33].

\section{Anatomical parameters}

After dissecting papillary muscle, right and left ventricles were separated and weighed. Lung fragments were weighed before and after drying sessions $\left(65^{\circ} \mathrm{C}\right.$ for $\left.72 \mathrm{~h}\right)$ to evaluate wet/dry weight ratio [34, 35].

\section{Biochemical analyses}

Glycemia was measured by the enzymatic method using glucose oxidase and peroxidase. Serum insulin concentration was determined by enzyme immune assay kit (EIA kit, Cayman Chemical, USA), using an ELISA reader (Biotech Instruments, Inc., USA) [36].

\section{Statistical analysis}

Results are expressed as mean \pm standard deviation. Statistical differences between groups were assessed by analysis of variance (ANOVA) in a factorial design $2 \times 2$ in the one-way model. The Tukey's post hoc test was used to compare individual groups, when the ANOVA revealed a significant F statistic. Statistical significance was accepted at $\mathrm{p}<0.05$. The statistical analyses were performed using Systat for Windows version 12.0 (Systat Software Inc, San Jose, CA, USA).

\section{Results}

None of the rats died during the experimental period. Forty-eight hours after streptozotocin administration, glycemia was significantly higher in diabetic than control groups (C 93.1 \pm 3.0 ; C-R $84.9 \pm 6.0$; DM $414 \pm 77$; $\mathrm{DM}-\mathrm{R} 417 \pm 78 \mathrm{mg} / \mathrm{dL})$. At the end of the experiment, glycemia was statistically higher in DM than DM-R and C and in DM-R than C-R (C $98.9 \pm 13.7$; C-R $104 \pm 11.9$; DM $397 \pm 57.5$; DM-R $149 \pm 30.3 \mathrm{mg} / \mathrm{dL}$ ). At the end of the study, serum insulin concentration was significantly lower in both diabetic groups compared to their respective controls (C $2.45 \pm 0.67$; C-R $2.09 \pm 0.52$; DM $0.59 \pm 0.18$; DM-R $0.82 \pm 0.21 \mathrm{ng} / \mathrm{mL}$ ).

Table 1 shows anatomical parameters. At the end of experiment, body weight (BW) was lower in DM and $\mathrm{DM}-\mathrm{R}$ than their respective controls and higher in DM-R than DM. LV and right ventricle weight was lower in DM and DM-R than controls.

Table 2 shows cardiac structural echocardiographic parameters evaluated at the end of the experimental period. C-R did not differ from C. Both DM and DM-R presented decreased septal wall thickness and relative wall thickness, and increased LV diastolic diameter/BW ratio than their respective controls. DM had increased LV systolic diameter compared to $C$, and increased left atrium diameter/BW ratio, and LV mass/BW ratio than both $\mathrm{C}$ and DM-R groups. DM-R presented lower LV posterior wall thickness, left atrium diameter, and LV mass than C-R, and lower septal wall thickness, LV

\section{Table 1 Anatomical parameters}

\begin{tabular}{lllll}
\hline Parameters & $\mathbf{C}(\mathbf{n}=\mathbf{1 4})$ & $\mathbf{C - R}(\mathbf{n}=\mathbf{1 4})$ & $\mathbf{D M}(\mathbf{n}=\mathbf{1 6})$ & $\begin{array}{l}\text { DM-R } \\
(\mathbf{n}=\mathbf{1 6})\end{array}$ \\
\hline BW Initial (g) & $365 \pm 24$ & $360 \pm 24$ & $409 \pm 34$ & $370 \pm 27$ \\
BW Final (g) & $444 \pm 42$ & $434 \pm 58$ & $287 \pm 33^{*}$ & $345 \pm 62^{\# 5}$ \\
LV weight (g) & $0.85 \pm 0.09$ & $0.77 \pm 0.13$ & $0.58 \pm 0.12^{*}$ & $0.68 \pm 0.10^{\#}$ \\
RV weight (g) & $0.25 \pm 0.04$ & $0.21 \pm 0.05^{*}$ & $0.17 \pm 0.05^{*}$ & $0.17 \pm 0.05^{\#}$ \\
Wet/dry Lung & $4.72 \pm 0.76$ & $4.72 \pm 0.92$ & $4.84 \pm 0.21$ & $4.98 \pm 0.55$
\end{tabular}

Data are expressed as mean \pm standard deviation or median and percentiles 25 and $75 \%$. One-way ANOVA in a factorial design $2 \times 2$ and Tukey's post hoc test.

$C$ untreated rats, $C-R$ rutin-treated rats, $D M$ untreated diabetic rats, $D M-R$ rutintreated diabetic rats, $B W$ body weight, $L V$ left ventricle, $R V$ right ventricle, Wet/dry wet-to-dry weight ratio.

${ }^{*} \mathrm{p}<0.05$ vs $\mathrm{C} ;{ }^{\#} \mathrm{p}<0.05$ vs $\mathrm{C}-\mathrm{R} ;{ }^{\S} \mathrm{p}<0.05$ vs DM. 
Table 2 Echocardiographic structural data

\begin{tabular}{|c|c|c|c|c|}
\hline Parameters & $C(n=14)$ & $C-R(n=14)$ & $\operatorname{DM}(n=16)$ & $\begin{array}{l}\text { DM-R } \\
(n=16)\end{array}$ \\
\hline $\mathrm{HR}(\mathrm{bpm})$ & $292 \pm 33$ & $293 \pm 32$ & $271 \pm 57$ & $283 \pm 30$ \\
\hline LVDD (mm) & $8.12 \pm 0.42$ & $8.21 \pm 0.36$ & $8.30 \pm 0.46$ & $8.35 \pm 0.51$ \\
\hline LVSD (mm) & $3.75 \pm 0.57$ & $3.91 \pm 0.34$ & $4.26 \pm 0.36^{*}$ & $3.97 \pm 0.50$ \\
\hline PWT (mm) & $1.53 \pm 0.11$ & $1.53 \pm 0.10$ & $1.46 \pm 0.07$ & $1.34 \pm 0.06^{\#}$ \\
\hline $\mathrm{SWT}(\mathrm{mm})$ & $1.65 \pm 0.05$ & $1.63 \pm 0.08$ & $1.48 \pm 0.10^{*}$ & $1.40 \pm 0.07^{\# 5}$ \\
\hline $\mathrm{LA}(\mathrm{mm})$ & $5.76 \pm 0.64$ & $6.03 \pm 0.71$ & $5.73 \pm 0.56$ & $5.36 \pm 0.53^{\#}$ \\
\hline $\begin{array}{l}\text { LVDD/BW } \\
(\mathrm{mm} / \mathrm{kg})\end{array}$ & $18.4 \pm 1.81$ & $19.2 \pm 2.11$ & $29.2 \pm 3.07^{*}$ & $24.7 \pm 3.26^{\# 5}$ \\
\hline $\begin{array}{l}\mathrm{LA} / \mathrm{BW}(\mathrm{mm} / \\
\mathrm{kg})\end{array}$ & $13.0 \pm 1.59$ & $14.1 \pm 2.47$ & $20.1 \pm 2.09^{*}$ & $16.0 \pm 2.85^{\S}$ \\
\hline LVM (g) & $0.94 \pm 0.10$ & $0.95 \pm 0.10$ & $0.89 \pm 0.12$ & $0.81 \pm 0.11^{\#}$ \\
\hline LVM/BW $(\mathrm{g} / \mathrm{kg})$ & $2.13 \pm 0.25$ & $2.23 \pm 0.30$ & $3.12 \pm 0.47^{*}$ & $2.38 \pm 0.23^{\S}$ \\
\hline RWT & $0.38 \pm 0.04$ & $0.38 \pm 0.04$ & $0.36 \pm 0.02^{*}$ & $0.32 \pm 0.02^{\# \S}$ \\
\hline
\end{tabular}

Data are expressed as mean \pm standard deviation. One-way ANOVA in a factorial design $2 \times 2$ and Tukey's post hoc test.

$C$ untreated rats, $C-R$ rutin-treated rats, $D M$ untreated diabetic rats, $D M-R$ rutintreated diabetic rats, $H R$ heart rate, LVDD and LVSD left ventricular (LV) diastolic and systolic diameter, respectively, PWT LV posterior wall thickness, SWT septal wall thickness, $L A$ left atrial diameter, LVM LV mass, RWT relative wall thickness, $B W$ body weight.

${ }^{*} p<0.05$ vs $C ; \# p<0.05$ vs $C-R ;{ }^{\S}<0.05$ vs DM.

diastolic diameter/BW ratio, and relative wall thickness than DM. Table 3 shows LV function. C-R did not differ from C. DM had reduced fractional shortening and posterior wall shortening velocity than C and DM-R. DM-R presented higher A wave and lower E/A ratio than DM.

Table 4 shows basal papillary muscle functional data. $\mathrm{DM}$ and DM-R presented higher time to peak of tension and time from peak tension to $50 \%$ relaxation than their respective controls. DM-R had a lower time to peak of tension than DM. Under 0.625 and $1.25 \mathrm{mM}$ extracellular calcium concentrations, DM had higher developed tension than C (Figure 1).

Table 3 Echocardiographic left ventricular functional data

\begin{tabular}{lllll}
\hline Parameters & $\mathbf{C}(\mathbf{n}=\mathbf{1 4})$ & $\mathbf{C - R}(\mathbf{n}=\mathbf{1 4})$ & $\mathbf{D M}(\mathbf{n}=\mathbf{1 6})$ & $\begin{array}{l}\text { DM-R } \\
(\mathbf{n}=\mathbf{1 6})\end{array}$ \\
\hline FS (\%) & $54.1 \pm 5.2$ & $52.5 \pm 2.87$ & $48.7 \pm 3.4^{*}$ & $52.6 \pm 4.2^{\S}$ \\
$\mathrm{PWSV}(\mathrm{mm} / \mathrm{s})$ & $44.5 \pm 4.6$ & $44.3 \pm 3.54$ & $35.5 \pm 5.4^{*}$ & $42.7 \pm 4.6^{\S}$ \\
$\mathrm{E}(\mathrm{cm} / \mathrm{s})$ & $74.1 \pm 11.7$ & $66.6 \pm 10.2$ & $75.1 \pm 14.3$ & $79.8 \pm 12.2^{\#}$ \\
$\mathrm{~A}(\mathrm{~cm} / \mathrm{s})$ & $52.9 \pm 11.3$ & $45.5 \pm 8.82$ & $48.1 \pm 18.1$ & $63.1 \pm 21.8^{\# \S}$ \\
E/A & $1.43 \pm 0.23$ & $1.51 \pm 0.31$ & $1.77 \pm 0.82$ & $1.36 \pm 0.34^{\S}$ \\
\hline
\end{tabular}

Data are expressed as mean \pm standard deviation. One-way ANOVA in a factorial design $2 \times 2$ and Tukey's post hoc test.

$C$ untreated rats, $C-R$ rutin-treated rats, $D M$ untreated diabetic rats, $D M-R$ rutintreated diabetic rats, FS endocardial fractional shortening, PWSV posterior wall shortening velocity, $E$ early diastolic mitral inflow velocity, $A$ late diastolic mitral inflow velocity, $E / A \mathrm{E} / \mathrm{A}$ ratio.

${ }^{*} \mathrm{p}<0.05$ vs $\mathrm{C} ;{ }^{\#} \mathrm{p}<0.05$ vs $\mathrm{C}-\mathrm{R} ;{ }^{\S} \mathrm{p}<0.05$ vs $\mathrm{DM}$.

\section{Discussion}

In this study we showed that rutin attenuated cardiac structural changes and left ventricular and myocardial dysfunction in rats with streptozotocin-induced diabetes mellitus.

Because of its toxic effect on pancreatic $\beta$-cells in the islets of Langerhans, streptozotocin has been widely used to induce type 1 diabetes mellitus in rodents [37-39]. As previously reported [37], streptozotocin-induced diabetes mellitus was characterized by body weight loss and increased blood glucose. Despite similar blood glucose levels $48 \mathrm{~h}$ after streptozotocin administration, rutin-treated rats presented attenuation in increased final blood glucose concentration and body weight loss. Administration of isoflavones or isolated rutin has been shown to exert an antihyperglycemic effect in humans with type 2 diabetes mellitus [40] and in experimental models such as streptozotocin-induced diabetes [41, 42] and obese Zucker rats [43]. At the end of our experiment, insulin levels did not statistically differ between DM-R and DM groups. A strong relationship was observed between flavonoids and glucose metabolism. In cell culture, flavonoid procyanidins had insulin-like effects on insulin sensitive cells [41]. This flavonoid effect could explain our result of reduced blood glucose levels despite unchanged insulin levels. Furthermore, flavonoids have been shown to depress gluconeogenic enzymes and inhibit glucose-6-phosphatase in the liver, consequently reducing blood glucose release [44].

Echocardiographic evaluation showed diabetic rats presenting left cardiac chambers dilation with increased LV mass and reduced relative wall thickness, which establishes a pattern of LV eccentric hypertrophy. Some authors did not observe statistically significant changes in echocardiography structures 8 weeks after inducing diabetes in rats [45]. It is probable that, in our study, by using a greater sample size, we could observe significant dilation in left cardiac chambers. Functionally, DM had systolic dysfunction characterized by decreased endocardial fractional shortening and posterior wall shortening velocity.

Several pathophysiological mechanisms can be involved in cardiac injury during diabetes $[23,46]$. Impaired myocardial contractility is a major cause of cardiac dilation and dysfunction [47]. We therefore evaluated myocardial function in LV papillary muscle preparations. Diabetes increased contraction and relaxation time. Under low extracellular calcium concentrations, DM had higher developed tension than $C$, which suggests that diabetes increased myocardial sensitivity to calcium. Alterations in contractile and relaxation function have been previously reported in rats with streptozotocin-induced 
Table 4 Isolated papillary muscle data at $2.50 \mathrm{mM}$ extracellular $\mathrm{Ca}^{2+}$ concentration

\begin{tabular}{lcccc}
\hline Parameters & $\mathbf{C}(\mathbf{n}=\mathbf{1 0})$ & $\mathbf{C - R}(\mathbf{n}=\mathbf{1 3})$ & DM $(\mathbf{n}=\mathbf{1 3})$ & $\mathbf{D M}-\mathbf{R}(\mathbf{n}=\mathbf{1 2})$ \\
\hline DT $\left(\mathrm{g} / \mathrm{mm}^{2}\right)$ & $5.83 \pm 0.86$ & $6.57 \pm 2.02$ & $7.00 \pm 0.85$ & $6.49 \pm 0.66$ \\
$\mathrm{TPT}(\mathrm{ms})$ & $148.23 \pm 7.45$ & $146.92 \pm 8.07$ & $195.12 \pm 8.07^{*}$ & $168.33 \pm 14.39^{\# \S}$ \\
$\mathrm{RT}_{1 / 2}$ & $159.86 \pm 29.59$ & $169.76 \pm 14.17$ & $224.62 \pm 5.27^{*}$ & $213.43 \pm 26.45^{\#}$ \\
$+\mathrm{dT} / \mathrm{dt}\left(\mathrm{g} / \mathrm{mm}^{2} / \mathrm{s}\right)$ & $59.54 \pm 9.53$ & $72.65 \pm 21.22$ & $66.65 \pm 7.71$ & $69.07 \pm 11.14$ \\
$-\mathrm{dT} / \mathrm{dt}\left(\mathrm{g} / \mathrm{mm}^{2} / \mathrm{s}\right)$ & $25.53 \pm 4.75$ & $26.93 \pm 7.02$ & $23.28 \pm 4.25$ & $21.98 \pm 3.16$ \\
$\mathrm{CSA}$ & $0.961 \pm 0.194$ & $0.962 \pm 0.294$ & $0.889 \pm 0.140$ & $0.951 \pm 0.144$ \\
\hline
\end{tabular}

Data are expressed as mean \pm standard deviation. One-way ANOVA in a factorial design $2 \times 2$ and Tukey's post hoc test.

$C$ untreated rats, $C-R$ rutin-treated rats, $D M$ untreated diabetic rats, $D M-R$ rutin-treated diabetic rats, $D T$ peak of developed tension, $T P T$ time to peak of tension, $R T_{1 / 2}$ time from peak tension to $50 \%$ relaxation, $+d T / d t$ maximum rate of tension development, $-d T / d t$ maximum rate of tension decline, CSA papillary muscle crosssectional area.

${ }^{*} \mathrm{p}<0.05$ vs $\mathrm{C} ;{ }^{\#} \mathrm{p}<0.05$ vs $\mathrm{C}-\mathrm{R} ;{ }^{\S} \mathrm{p}<0.05$ vs DM.

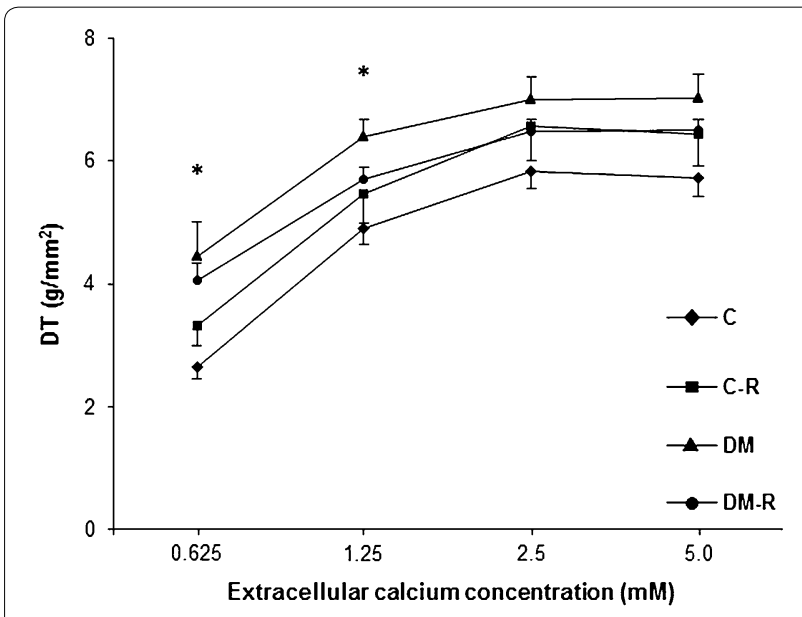

Figure 1 Peak of developed tension (DT) under different extracellular calcium concentrations. C untreated rats, C- $R$ rutin-treated rats, DM untreated diabetic rats, $D M-R$ rutin-treated diabetic rats. Values are mean and standard error; Anova and Tukey; ${ }^{*} p<0.05$ DM vs C.

diabetes $[23,48,49]$. Data on myofibrils sensitivity to calcium are controversial in diabetes [50-53]. Our results are in accordance with some experimental studies. Electrophysiological analysis in rats with alloxan-induced diabetes showed increased muscle sensitivity to a decrease in external calcium [51]. Also skinned fibers from diabetic rats showed a slight increase in calcium sensitivity [54]. This increased calcium sensitivity may have played a role in the slow relaxation time-course characterized by increased time from peak tension to $50 \%$ relaxation in DM. Other factors such as lower myosin ATPase activity and abnormal myosin isoenzyme distribution may have contributed to the increased time to peak of tension observed in the DM group [55].

Cardiac parameters in the normoglycemic rats were not changed by rutin, except for reduced right ventricle weight. In the diabetic rats, rutin prevented LV hypertrophy, left atrium dilation, and systolic dysfunction, attenuated LV dilation, and decreased relative wall thickness, thus characterizing cardiac changes as LV eccentric remodeling with preserved systolic function. Myocardial dysfunction was also attenuated by rutin, as time to peak tension was lower in DM-R than DM. Under lower extracellular calcium concentrations, DM-R presented developed tension values between those of C-R and DM and did not significantly differ from either group. Therefore, rutin attenuated cardiac remodeling and myocardial dysfunction in rats with streptozotocin-induced diabetes.

Several beneficial effects of rutin have been shown in different cardiac injury models. In rats fed a high carbohydrate and fat diet, rutin attenuated metabolic changes and cardiac remodeling [56]. In control and diabetic rats, rutin had a cardioprotective role against ischaemia-reperfusion injury $[16,57]$. In a clinical setting, this flavonoid decreased systemic blood pressure in diabetic patients [40]. The beneficial effects of flavonoids have been associated with different mechanisms including antiinflammatory, antiallergic, antiviral, and anticarcinogenic properties [15]. However, one of their most important actions is the anti-oxidant effect [15, 58]. Flavonoids stabilize reactive oxygen species by reacting with the reactive compound of the radical. Rutin can inhibit activity of xanthine oxidase, interfere with inducible nitric-oxide synthase activity, inhibit lipoperoxidation and advanced glycation end product generation, and protect against mitochondrial damage and iron chelation [15, 42, 59-61]. In neonatal rat heart myocyte culture, rutin also increased superoxide dismutase activity [57]. Several studies have shown the anti-oxidant potential of flavonoids in diabetes and other diseases [19, 42, 62]. In control and diabetic rats, rutin attenuated oxidative stress and increased antioxidant reserves during ischaemia-reperfusion injury $[16,57]$. As oxidative stress plays 
an important role in the pathophysiology of diabetic cardiomyopathy [22, 23], this study allows us to propose the hypothesis that rutin attenuated diabetes-induced cardiac remodeling and dysfunction through its anti-oxidant properties. Additional studies are needed to clarify the mechanisms of rutin-induced beneficial effects on diabetic cardiomyopathy.

In conclusion, rutin attenuates cardiac remodeling and left ventricular and myocardial dysfunction caused by streptozotocin-induced diabetes mellitus.

\begin{abstract}
Abbreviations
ANOVA: analysis of variance; A wave: late diastolic mitral inflow velocity; BW: body weight; C: control group; C-R: control-rutin group; CSA: papillary muscle cross-sectional area; DM: diabetes mellitus group; DM-R: DM-rutin group; DT: peak of developed tension; $-\mathrm{dT} / \mathrm{dt}$ : maximum rate of tension decline; $+\mathrm{dT} / \mathrm{dt}$ maximum rate of tension development; E/A: E/A ratio; E wave: early diastolic mitral inflow velocity; FS: endocardial fractional shortening; HR: heart rate; $K O$ : Katashi Okoshi; LA: left atrium diameter; LV: left ventricular; LVDD: left ventricular diastolic diameter; LVM: left ventricular mass; LVSD: left ventricular systolic diameter; PWSV: posterior wall shortening velocity; PWT: left ventricular diastolic posterior wall thickness; $\mathrm{RT}_{1 / 2}$ : time from peak tension to $50 \%$ relaxation; RWT: left ventricular relative wall thickness; STZ: streptozotocin; SWT: left ventricular diastolic septal wall thickness; TPT: time to peak of tension.
\end{abstract}

\section{Authors' contributions}

JFCG and BPM contributed to conception, design, and data collection; AFN, MMS, AAHF, ACC, and CRP contributed to data collection and analysis; CMR and MPO contributed to manuscript writing; KO contributed to conception and design, data acquisition, data analysis and interpretation, and manuscript writing. All authors read and approved the final manuscript.

\section{Author details}

${ }^{1}$ Department of Internal Medicine, Botucatu Medical School, Sao Paulo State University, UNESP, Botucatu, Brazil. ${ }^{2}$ Department of Chemistry and Biochemistry, Institute of Biosciences, Sao Paulo State University, UNESP, Botucatu, Brazil. ${ }^{3}$ Departamento de Clinica Medica, Faculdade de Medicina de Botucatu, UNESP Rubiao Junior, S/N 18618-970, Botucatu, SP, Brazil.

\section{Acknowledgements}

We are grateful to Jose C Georgette for their technical assistance and Colin Edward Knaggs for English editing. Financial support was provided by CAPES, CNPq (306845/2012-1 and 306857/2012-0), FAPESP (2009/54506-7), and PROPe, UNESP.

\section{Compliance with ethical guidelines}

Competing interest

The authors declare that they have no competing interests.

Received: 7 May 2015 Accepted: 3 July 2015

Published online: 17 July 2015

\section{References}

1. Tsiachris D, Tsioufis C, Thomopoulos C, Syrseloudis D, Antonakis V, Lioni Let al (2011) New-onset diabetes and cardiovascular events in essential hypertensives: a 6-year follow-up study. Int J Cardiol 153:154-158

2. Go AS, Mozaffarian D, Roger VL, Benjamin EJ, Berry JD, Blaha MJ et al (2014) Heart disease and stroke statistics - 2014 update: a report from the American Heart Association. Circulation 129:e28-e292

3. Rubler S, Dlugash J, Yuceoglu YZ, Kumral T, Branwood AW, Grishman A (1972) New type of cardiomyopathy associated with diabetic glomerulosclerosis. Am J Cardiol 30:595-602
4. Seferović PM, Paulus WJ (2015) Clinical diabetic cardiomyopathy: a twofaced disease with restrictive and dilated phenotypes. Eur Heart J (in press)

5. Miki T, Yuda S, Kouzu H, Miura T (2013) Diabetic cardiomyopathy: pathophysiology and clinical features. Heart Fail Rev 18:149-166

6. Li CJ, Lv L, Li H, Yu DM (2012) Cardiac fibrosis and dysfunction in experimental diabetic cardiomyopathy are ameliorated by alpha-lipoic acid. Cardiovasc Diabetol 11:73

7. Fuentes-Antrás J, Picatoste B, Ramírez E, Egido J, Tuñón J, Lorenzo O (2015) Targeting metabolic disturbance in the diabetic heart. Cardiovasc Diabetol 14:17

8. Aksakal E, Akaras N, Kurt M, Tanboga IH, Halici Z, Odabasoglu F et al (2011) The role of oxidative stress in diabetic cardiomyopathy: an experimental study. Eur Rev Med Pharmacol Sci 15:1241-1246

9. Liu Q, Wang S, Cai L (2014) Diabetic cardiomyopathy and its mechanisms: role of oxidative stress and damage. J Diabetes Invest 5:623-634

10. Zhang S, Liu H, Amarsingh GV, Cheung CC, Hogl S, Narayanan U et al (2014) Diabetic cardiomyopathy is associated with defective myocellular copper regulation and both defects are rectified by divalent copper chelation. Cardiovasc Diabetol 13:100

11. Maraldi T (2013) Natural compounds as modulators of NADPH oxidases. Oxid Med Cell Longev 2013:271602

12. Matough FA, Budin SB, Hamid ZA, Alwahaibi N, Mohamed J (2012) The role of oxidative stress and antioxidants in diabetic complications. Sult Qaboos Univ Med J 12:5-18

13. Freidja ML, Vessières E, Toutain B, Guihot AL, Custaud MA, Loufrani L et al (2014) AGEs breaking and antioxidant treatment improves endotheliumdependent dilation without effect on flow-mediated remodeling of resistance arteries in old Zucker diabetic rats. Cardiovasc Diabetol 13:55

14. Oyenihi AB, Ayeleso AO, Mukwevho E, Masola B (2015) Antioxidant strategies in the management of diabetic neuropathy. Biomed Res Int 2015:515042

15. Nijveldt RJ, van Nood E, van Hoorn DE, Boelens $\mathrm{PG}$, van Norren $\mathrm{K}$, van Leeuwen PA (2001) Flavonoids: a review of probable mechanisms of action and potential applications. J Clin Nutr 74:418-425

16. Annapurna A, Reddy CS, Akondi RB, Rao SR (2009) Cardioprotective actions of two bioflavonoids. Quercetin and rutin in experimental myocardial infarction in both normal and streptozotocin-induced type I diabetic rats. J Pharm Pharmacol 61:1365-1374

17. Wang J, Sarnola K, Ruotsalainen S, Moilanen L, Lepisto P, Laakso M et al (2010) The metabolic syndrome predicts incident congestive heart failure: a 20-year follow-up study of elderly Finns. Atherosclerosis 210:237-242

18. Boudina S, Abel ED (2007) Diabetic cardiomyopathy revisited. Circulation 115:3213-3223

19. Wang YB, Ge ZM, Kang WQ, Lian ZX, Yao J, Zhou CY (2015) Rutin alleviates diabetic cardiomyopathy in a rat model of type 2 diabetes. Exp Ther Med 9:451-455

20. Kilkenny C, Browne WJ, Cuthill IC, Emerson M, Altman DG (2010) Improving bioscience research reporting: the ARRIVE guidelines for reporting animal research. PLoS Biol 8:e1000412

21. Fernandes AAH, Novelli EL, Okoshi K, Okoshi MP, Di Muzio BP, Guimarães JFC et al (2010) Influence of rutin treatment on biochemical alterations in experimental diabetes. Biomed Pharmacother 64:214-219

22. Gimenes C, Gimenes R, Rosa CM, Xavier NP, Campos DHS, Fernandes AAH et al (2015) Low intensity physical exercise attenuates cardiac remodeling and myocardial oxidative stress and dysfunction in diabetic rats. J Diabetes Res (in press)

23. Rosa CM, Xavier NP, Campos DHS, Fernandes AAH, Cezar MDM, Martinez PF et al (2013) Diabetes mellitus activates fetal gene program and intensifies cardiac remodeling and oxidative stress in aged spontaneously hypertensive rats. Cardiovasc Diabetol 12:152

24. Okoshi K, Matsubara LS, Okoshi MP, Cicogna AC, Fioretto JR, Padovani CR et al (2002) Food restriction-induced myocardial dysfunction demonstrated by the combination of in vivo and in vitro studies. Nutr Res 22:1353-1364

25. Okoshi K, Ribeiro HB, Okoshi MP, Matsubara BB, Gonçalves G, Barros R et al (2004) Improved systolic ventricular function with normal myocardial mechanics in compensated cardiac hypertrophy. Jpn Heart J 45:647-656 
26. Lima ARR, Martinez PF, Okoshi K, Guizoni DM, Zornoff LAM, Campos DHS et al (2010) Myostatin and follistatin expression in skeletal muscles of rats with chronic heart failure. Int J Exp Path 91:54-62

27. Martinez PF, Okoshi K, Zornoff LAM, Oliveira SA Jr, Campos DHS, Lima ARR et al (2011) Echocardiographic detection of congestive heart failure in postinfarction rats. J Appl Physiol 111:543-551

28. Okoshi MP, Matsubara LS, Franco M, Cicogna AC, Matsubara BB (1997) Myocyte necrosis is the basis for fibrosis in renovascular hypertensive rats. Braz J Med Biol Res 30:1135-1144

29. Cicogna AC, Padovani CR, Okoshi K, Matsubara LS, Aragon FF, Okoshi MP (2001) The influence of temporal food restriction on the performance of isolated cardiac muscle. Nutr Res 21:639-648

30. Okoshi MP, Okoshi K, Dal Pai V, Dal Pai-Silva M, Matsubara LS, Cicogna AC (2001) Mechanical, biochemical, and morphological changes in the heart from chronic food-restricted rats. Can J Physiol Pharmacol 79:754-760

31. Gut AL, Okoshi MP, Padovani CR, Aragon FF, Cicogna AC (2003) Myocardial dysfunction induced by food restriction is related to calcium cycling and beta-adrenergic system changes. Nutr Res 23:911-919

32. Sugizaki MM, Carvalho RF, Aragon FF, Padovani CR, Okoshi K, Okoshi MP et al (2005) Myocardial dysfunction induced by food restriction is related to morphological damage in normotensive middle-aged rats. J Biomed Sci 12:641-649

33. Cicogna AC, Matsubara BB, Matsubara LS, Okoshi K, Gut AL, Padovani CR et al (2002) Volume overload influence on hypertrophied myocardium function. Jpn Heart J 43:689-695

34. Damatto RL, Martinez PF, Lima AR, Cezar MD, Campos DH, Oliveira SA Jr et al (2013) Heart failure-induced skeletal myopathy in spontaneously hypertensive rats. Int J Cardiol 167:698-703

35. Martinez PF, Okoshi K, Zornoff LA, Carvalho RF, Oliveira SA Jr, Lima AR et al (2010) Chronic heart failure-induced skeletal muscle atrophy, necrosis, and myogenic regulatory factors changes. Med Sci Monit 16:374-383

36. Oliveira SA Jr, Padovani CR, Rodrigues SA, Silva NR, Martinez PF, Campos DH et al (2013) Extensive impact of saturated fatty acids on metabolic and cardiovascular profile in rats with diet-induced obesity: a canonical analysis. Cardiovasc Diabetol 12:65

37. Sarkhail P, Rahmaipour S, Fadyevatan S, Mohammadirad A, Dehghan G, Amin G (2007) Antidiabetic effect of Phlomis anisodonta: effects on hepatic cells lipid peroxidation and antioxidant enzymes in experimental diabetes. Pharmacol Res 51:261-266

38. Kumar S, Singh R, Vasudeva N, Sharma S (2012) Acute and chronic animal models for the evaluation of anti-diabetic agentes. Cardiovasc Diabetol $11: 9$

39. Gao Y, Kang L, Li C, Wang X, Sun C, Li Q (2015) Resveratrol ameliorates diabetes-induced cardiac dysfunction through AT1R-ERK/p38 MAPK signaling pathway. Cardiovasc Toxicol (in press)

40. Sattanathan K, Dhanapal CK, Umarani R, Manavalan R (2011) Beneficial health effects of rutin supplementation in patients with diabetes mellitus. J App Pharm Sci 2011:227-231

41. Pinent M, Blay M, Bladé MC, Salvadó MJ, Arola L (2004) Grape seedderived procyanidins have an antihyperglycemic effect in streptozotocininduced diabetic rats and insulinomimetic activity in insulin-sensitive cell lines. Endocrinology 145:4985-4990

42. Kamalakkannan N, Prince PS (2006) Antihyperglycaemic and antioxidant effect of rutin, a polyphenolic flavonoid, in streptozotocin-induced diabetic wistar rats. Basic Clin Pharmacol Toxicol 98:97-103

43. Mezei O, Banz WJ, Steger RW, Peluso MR, Winters TA, Shay N (2003) Soy isoflavones exert antidiabetic and hypolipidemic effects through the PPAR pathways in obese zucker rats and murine RAW 264.7 cells. J Nutr 133:1238-1243

44. Naik SR, Fliho JMB, Dhuley JN, Deshmukh A (1999) Probable mechanism of hypoglycaemic activity of bassic acid, a natural product isolated from Bumelia sartorum. J Ethnopharmacol 33:37-44

45. Akula A, Kota MK, Gopisetty SG, Chitrapu RV, Kalagara M, Kalagara S et al (2003) Biochemical, histological and echocardiographic changes during experimental cardiomyopathy in STZ-induced diabetic rats. Pharmacol Res 48:429-435

46. Bugger H, Abel ED (2014) Molecular mechanisms of diabetic cardiomyopathy. Diabetologia 57:660-671

47. Opie LH, Hasenfuss G (2012) Mechanisms of cardiac contraction and relaxation. In: Bonow RO, Mann DL, Zipes DP, Libby P, Braunwald E (eds)
Braunwald's Heart Disease. A textbook of cardiovascular medicine. 8th edn. Elsevier Saunders, Philadelphia, pp 459-486

48. Ares-Carrasco S, Picatoste B, Camafeita E, Carrasco-Navarro S, Zubiri I, Ortiz A et al (2012) Proteome changes in the myocardium of experimental chronic diabetes and hypertension: role of PPAR $\alpha$ in the associated hypertrophy. J Proteomics 75:1816-1829

49. Falcão-Pires I, Leite-Moreira AF (2012) Diabetic cardiomyopathy: understanding the molecular and cellular basis to progress in diagnosis and treatment. Heart Fail Rev 17:325-344

50. Pierce GN, Dhalla NS (1981) Cardiac myofibrillar ATPase activities in diabetic rats. J Mol Cell Cardiol 13:1063-1069

51. Sauviat MP, Feuvray D (1986) Electrophysiological analysis of the sensitivity to calcium in ventricular muscle from alloxan diabetic rats. Basic Res Cardiol 81:489-496

52. Ward ML, Crossman DJ (2014) Mechanisms underlying the impaired contractility of diabetic cardiomyopathy. World J Cardiol 6:577-584

53. Malhotra A, Sanghi V (1997) Regulation of contractile proteins in diabetic heart. Cardiovasc Res 34:34-40

54. Murat I, Veksler VI, Ventura-Clapier R (1989) Effects of halothane on contractile properties of skinned fibers from cardiomyopathic animals. J Mol Cell Cardiol 21:1293-1304

55. Dillmann WH (1982) Influence of thyroid hormone administration on myosin ATPase activity and myosin isoenzyme distribution in the heart of diabetic rats. Metabolism 31:199-204

56. Panchal SK, Poudyal H, Arumugam TV, Brown L (2011) Rutin attenuates metabolic changes, nonalcoholic steatohepatitis, and cardiovascular remodeling in high-carbohydrate, high-fat diet-fed rats. J Nutr 141:1062-1069

57. Bhandary B, Piao CS, Kim DS, Lee GH, Chae SW, Kim HR, Chae HJ (2012) The protective effect of rutin against ischemia/reperfusion-associated hemodynamic alteration through antioxidant activity. Arch Pharm Res 35:1091-1097

58. Kandemir FM, Ozkaraca M, Yildirim BA, Hanedan B, Kirbas A, Kilic Ket a (2015) Rutin attenuates gentamicin-induced renal damage by reducing oxidative stress, inflammation, apoptosis, and autophagy in rats. Ren Fail 23:1-8

59. Punithavathi VR, Shanmugapriya K, Prince PS (2010) Protective effects of rutin on mitochondrial damage in isoproterenol-induced cardiotoxic rats: an in vivo and in vitro study. Cardiovasc Toxicol 10:181-189

60. Muthenna P, Akileshwari C, Saraswat M, Bhanuprakash RG (2012) Inhibition of advanced glycation end-product formation on eye lens protein by rutin. Br J Nutr 107:941-949

61. Kappel VD, Zanatta L, Postal BG, Silva FR (2013) Rutin potentiates calcium uptake via voltage-dependent calcium channel associated with stimulation of glucose uptake in skeletal muscle. Arch Biochem Biophys 532:55-60

62. Fernandes AAH, Novellil ELB, Fernandes Junior A, Galhardi CM (2009) Effect of naringerin on biochemical parameters in the streptozotocininduced diabetic rats. Braz Arch Biol Technol 52:51-59

\section{Submit your next manuscript to BioMed Central and take full advantage of:}

- Convenient online submission

- Thorough peer review

- No space constraints or color figure charges

- Immediate publication on acceptance

- Inclusion in PubMed, CAS, Scopus and Google Scholar

- Research which is freely available for redistribution

Submit your manuscript at

www.biomedcentral.com/submit
( Biomed Central 